\title{
Exchange rate pass-through and inflation targeting in Peru
}

\author{
Diego Winkelried * \\ Central Reserve Bank of Peru \\ Jr. Miroquesada 441, Lima 1, Perú \\ diego.winkelried@bcrp.gob.pe \\ diegowq@cantab.net
}

July 18, 2011

\begin{abstract}
It has been widely documented that the exchange rate pass-through to domestic inflation has decreased significantly in most of the industralised world. As microeconomic factors cannot completely explain such a widespread phenomenon, a macroeconomic explanation linked to the inflationary environment that a low and more stable inflation rate leads to a decrease in the pass-through - have gained popularity. Using a structural VAR framework, this paper presents evidence of a similar decline in the pass-through in Peru, a small open economy that gradually reduced inflation to international levels in order to adopt a fully-fledged inflation targeting scheme in 2002. It is argued that the establishment of a credible regime of low inflation has been instrumental in driving the exchange rate pass-through down.
\end{abstract}

JEL Classification : C32, E31, E47, F31.

Keywords $\quad:$ Exchange rate pass-through, inflation targeting, structural VAR.

*I would like to thank Adrián Armas, César Carrera and seminar participants at the Central Reserve Bank of Peru for helpful comments. The usual disclaimer applies. 


\section{Introduction}

In open economies, exchange rate fluctuations affect the behaviour of domestic inflation, the so-called exchange rate pass-through effect. The magnitude of this effect is key for the design of monetary policy, as it determines whether the central bank should devote efforts to control nominal depreciatory pressures that may jeopardise price stability. Moreover, recent studies such as Flamini (2007) and Adolfson (2007) point out that the characteristics of the pass-through may even affect the choice of the measure of inflation the central bank should target: either inflation involving exclusively locally produced goods or total inflation that includes imports.

Consider inflation as typically measured by the percent change in a Consumer Price Index (CPI). The pass-through effect manifests itself essentially through two channels. The first one is direct: some of the goods that compose the CPI basket are imports or close substitutes to imports. An increase in the exchange rate (local currency per US dollar) immediately makes the price of goods purchased in US dollars, expressed in local currency, higher. Given a more expensive dollar, importers will adjust their prices in local currency to maintain their markups, so that consumers end up paying a higher amount of money in local currency to purchase the same good, thereby generating inflation 1

The second channel can be regarded as a distribution chain of goods with three stages. Although most of the items in the CPI are locally produced, their manufacturing may require imported inputs that are priced in dollars. In the first stage, an increase in the exchange rate leads to higher prices, in local currency, of such inputs. In the second stage, importers transfer the increase to local producers who experience an increase in their productions costs. The third stage involves local producers aiming to maintain a markup charging higher prices to consumers. Thus, the initial depreciation found its way to consumer prices, and therefore to inflation. Clearly, distribution costs and nominal rigidities at each stage play a role in buffering the impact of currency depreciation as it moves forward the distribution chain.

As it can be deduced, the magnitude of the pass-through is tightly related to the ability of importers and producers to transfer their higher costs to consumers. This ability depends, at first glance, on microeconomic factors such as the degree of substitution among goods and the degree of competition in the economy (Goldberg and Knetter, 1997). For instance, Marazzi and Sheets (2007) observe, during the last decades, a sustained decline in the pass-through from exchange rate to import prices in the US. They attribute the decline to factors that promote competition and improve the substitution possibilities among consumer goods. A similar decreasing trend in the pass-through for OECD countries is stressed in Campa and Goldberg (2005), who argue that it is due to a profound change in the composition of the imports bundle.

In fact, there is a vast literature documenting the substantially weaker influence of exchange rate on inflation in industrialised economies during the 90s, compared to the 70s and 80s (see Takhtamanova, 2010, and the references therein). Evidence for the same phenomenon for emerging markets, though not as voluminous and clear-cut, is given in Mihaljek and Klau (2008). The reduction in the exchange rate pass-through seems to be so fast, so pronounced and so pervasive that it is difficult to be explained satisfactorily solely with microeconomic considerations. This is due to the fact that the pass-through effect is likely to be influenced by macroeconomic factors as well.

In this respect, Taylor (2000) offers an interesting interpretation: the decline in the pass-through in industralised economies is the result of the low inflation environment experienced by these countries during the 90s, in contrast to the high inflation rates recorded for previous decades. At this point, it is key to understand how exchange rate shocks are perceived by importers and producers. If the increase in costs following a depreciation is perceived as transitory, agents can reduce temporarily their markups, save the menu costs of changing prices and simply wait until the shock reverts. On the contrary, if the shock is perceived as permanent or highly persistent, the price adjustment is inevitable. Since the economy will be subject to more persistent nominal shocks in high inflation regimes, the link between the level of inflation and the pass-through emerges. In the same line, importers and producers will find it easier to increase their prices more frequently, e.g. the consumers would be less reluctant to such increases, in a high inflation environment. This hypothesis has been put to the test successfully by Carrera and Binici (2006),

\footnotetext{
${ }^{1}$ This channel is stronger if prices of some non-tradable goods or services, for instance rent, are set in dollars. In the Peruvian case, about 20 percent of items in Lima CPI (the inflation indicator the central bank targets) are either imported or priced in dollars.
} 


\section{Choudhri and Hakura (2006) and Takhtamanova (2010).}

An important monetary policy implication, especially for emerging markets, is that if the central bank manages to establish a credible low inflation regime, then exchange rate pass-through should decline quickly. This hypothesis seems more relevant in countries that have adopted an inflation targeting regime, following the findings in Vega and Winkelried (2005): the adoption of such a scheme in the developing world has significantly contributed to reductions in both the level and volatility of inflation. Indeed, many of these economies have reached low and stable inflation levels by the end of the 90s. Thus, it is likely that they have experienced, with a one decade lag, the decline in the pass-through observed in the industrialised world.

The purpose of this paper is to evaluate the effects of the adoption of an inflation targeting regime on the exchange rate pass-through in Peru 2 The pass-through effect is defined as a normalised inflation response to an exchange rate shock in a structural VAR framework that models explicitly the different stages of the distribution chain, following McCarthy (2007). To assess time variation in the estimated pass-through, and to have an appraisal of the effect of adopting an inflation targeting regime, we use rolling windows such that the first subsamples predate the adoption of the regime, whereas the last windows include only observations drawn from the new monetary policy regime. The recent Peruvian inflationary history shares several similarities with that of other emerging markets. Thus, we believe our analysis can be easily extended to other experiences in developing countries.

The rest of the paper is organised as follows. Section 2 presents the econometric framework. In particular, it develops a metric, built upon the impulse response function in a structural VAR setup, that can be naturally interpreted as the pass-through effect. Section 3 briefs the Peruvian disinflation experience towards the adoption of a fully-fledged inflation targeting regime in 2002. This allows us to understand the dynamics of the pass-through effect, which exhibits a notable decline by the time the inflation targeting scheme was adopted. Furthermore, several sensitivity analyses are conducted and it is concluded that the downward shift in the pass-through is a robust feature of the data. Section 4 concludes and gives some avenues for future research.

\section{Methodology}

A standard way to estimate the pass-through effects is as the coefficient obtained from regressing changes in price indices on variations in nominal exchange rates (see inter alia Campa and Goldberg, 2005; Mihaljek and Klau, 2008). This practice, however, is not necessarily well suited as it implicitly suggests that any movement in the exchange rate is exogenous, while failing to control for factors, other than the exchange rate, that determine inflation. A multivariate analysis is called for.

Following Clark (1999) and McCarthy (2007), we perform a vector autoregressive (VAR) analysis, where the degree of pass-through can be computed as the responsiveness of domestic prices (including consumer prices, producer prices and import prices) to an unexpected movement in the exchange rate shock. The structural form of the VAR model can be regarded as a simple aggregate model of pricing along the distribution chain 3

\subsection{Measuring the pass-through effect}

Consider the VAR model,

$$
\boldsymbol{y}_{t}=\boldsymbol{\alpha}+\boldsymbol{A}(L) \boldsymbol{y}_{t-1}+\boldsymbol{\varepsilon}_{t} \quad \text { where } \quad \mathbb{E}\left(\boldsymbol{\varepsilon}_{t}\right)=\mathbf{0}, \quad \mathbb{E}\left(\boldsymbol{\varepsilon}_{t} \boldsymbol{\varepsilon}_{t}{ }^{\prime}\right)=\boldsymbol{\Omega} \quad \text { and } \quad \mathbb{E}\left(\boldsymbol{\varepsilon}_{t} \boldsymbol{\varepsilon}_{s}{ }^{\prime}\right)=\mathbf{0} \text { for } t \neq s .
$$

where $\boldsymbol{y}_{t}$ is an $n \times 1$ vector of jointly determined dependent variables and $\boldsymbol{A}(L)=\boldsymbol{A}_{1} L+\boldsymbol{A}_{2} L^{2}+\ldots+\boldsymbol{A}_{m} L^{m}$, where $\boldsymbol{A}_{i}(i=1,2, \ldots, m)$ are $n \times n$ and coefficient matrices. The $n \times n$ covariance matrix of the VAR innovations $\boldsymbol{\Omega}$ is

\footnotetext{
${ }^{2}$ For previous studies on the exchange rate pass-through in Peru, see Winkelried (2003), Castillo et. al. (2011) and the references therein.

${ }^{3}$ It is worth-mentioning that a rather popular tool to analyse pass-through effects is the Error Correction Model (ECM), which is just a VAR model in differences (e.g., inflation rates) augmented by a term to preserve cointegration among the levels (e.g., price indices). However, as stressed by Hendry (2006), inferences based on the ECM's forecast function (tightly related to the IRF) can be seriously distorted due to deterministic breaks in the underlying cointegrating relationships. In view of this, we follow Hendry's recommendation of ignoring the error-correcting terms and work with a VAR in differences. This approach should render more robust inferences when the data is suspected to be subject to deterministic breaks (either temporary or permanent).
} 
positive definite.

A key quantity for our analysis is the cumulative impulse response function (IRF). An IRF measures the time profile of the effect of perturbations on the expected future values of variables in a dynamical system. The most convenient way to describe a cumulative IRF is as the outcome of the comparison between the time profile of $\boldsymbol{y}_{t+h}$ under the effect of innovations $\boldsymbol{\varepsilon}_{s}=\boldsymbol{\delta}$ hitting the economy from time $t$ onwards (i.e., for $s \geq t$ and $s \leq t+h$ ), and the profile in the absence of such perturbations $\left(\boldsymbol{\varepsilon}_{s}=\mathbf{0}\right)$. For a linear model like (1), the cumulative IRF is given by

$$
\Psi_{h} \boldsymbol{\delta},
$$

where $\boldsymbol{\Psi}_{h}=\boldsymbol{I}_{n}+\boldsymbol{\Theta}_{1}+\boldsymbol{\Theta}_{2}+\ldots+\boldsymbol{\Theta}_{h}$, and $\boldsymbol{\Theta}_{i}(i=1,2, \ldots)$ are the $n \times n$ matrices associated with the VMA representation $\boldsymbol{y}_{t}=\boldsymbol{\mu}+\boldsymbol{\varepsilon}_{t}+\boldsymbol{\Theta}_{1} \boldsymbol{\varepsilon}_{t-1}+\boldsymbol{\Theta}_{2} \boldsymbol{\varepsilon}_{t-2}+\ldots$ It is well-established that $\boldsymbol{\Psi}_{0}=\boldsymbol{I}_{n}$ and $\boldsymbol{\Psi}_{\infty}=\left[\boldsymbol{I}_{n}-\boldsymbol{A}(1)\right]^{-1}$.

Clearly, the implementation of (2) depends on the composition of innovations defined by $\delta$. However, it is often difficult to give a clear conceptual meaning to $\varepsilon_{t}$. The traditional approach to overcome this difficulty is to impose a structure linking the $n$ VAR innovations to $n$ structural shocks that can be given an economic interpretation. Such a restriction takes the linear form $\boldsymbol{\varepsilon}_{t}=\boldsymbol{B} \boldsymbol{u}_{t}$, where $\boldsymbol{B}$ is an $n \times n$ nonsingular matrix and $\boldsymbol{u}_{t}$ is the vector of shocks, so that $\boldsymbol{\varepsilon}_{t}=\boldsymbol{\delta}$ is associated with $\boldsymbol{u}_{t}=\boldsymbol{B}^{-1} \boldsymbol{\delta}=\boldsymbol{\delta}^{*}$, such that (2) can be written as $\boldsymbol{\Psi}_{h} \boldsymbol{B} \boldsymbol{\delta}^{*}$. It follows that the $n \times 1$ vector of the cumulative IRF of a unit impulse to the $k$-th structural shock on $\boldsymbol{y}_{t+h}$ is given by $\boldsymbol{\Psi}_{h} \boldsymbol{B} \boldsymbol{e}_{k}$, where $\boldsymbol{e}_{k}$ is an $n \times 1$ selection vector with unity as its $k$-th element and zeros elsewhere. Thus, this shock sets $\boldsymbol{\delta}^{*}=\boldsymbol{e}_{k}$.

Suppose that we identify an exchange rate shock as being the $k$-th element of $\boldsymbol{u}_{t}$. In addition, let the $j$-th element of $\boldsymbol{y}_{t}$ be a measure of nominal depreciation, and the $i$-th element of $\boldsymbol{y}_{t}$ be the measure of inflation under study. Then, we define the pass-through effect of the exchange rate shock after $h$ periods as

$$
\psi_{h}(i)=\frac{\boldsymbol{e}_{i}^{\prime} \boldsymbol{\Psi}_{h} \boldsymbol{B} \boldsymbol{e}_{k}}{\boldsymbol{e}_{j}^{\prime} \Psi_{h} \boldsymbol{B} \boldsymbol{e}_{k}}
$$

After $h$ periods, the exchange rate shock has an accumulated effect of $\boldsymbol{e}_{j}{ }^{\prime} \boldsymbol{\Psi}_{h} \boldsymbol{B} \boldsymbol{e}_{k}$ on the nominal depreciation. Thus, given the linearity of (1), setting $\delta^{*}=\boldsymbol{e}_{k} /\left(\boldsymbol{e}_{j}{ }^{\prime} \boldsymbol{\Psi}_{h} \boldsymbol{B} \boldsymbol{e}_{k}\right)$ renders a shock that produces a nominal depreciation of exactly one percent after $h$ periods. The definition of (3) is simply the cumulative response of inflation to such a shock, and can be regarded as the fraction of the one percent depreciation that passes through domestic prices. This seems to be the natural way to infer on pass-through effects in a multivariate framework. Moreover, expression (3) itself and its standard error (using the delta method) can be readily computed from the standard output in structural VAR estimation.

\subsection{Base model}

We consider a $n=6$ variable VAR for $\boldsymbol{y}_{t}=\left(\pi_{t}^{*}, a_{t}, s_{t}, \pi_{t}^{m}, \pi_{t}^{w}, \pi_{t}^{c}\right)^{\prime}$, where $\pi_{t}^{*}$ is foreign inflation (in US\$), $a_{t}$ measures economic activity, $s_{t}$ is nominal depreciation (the percent change of the price of local currency per US\$), and $\pi_{t}^{m}$, $\pi_{t}^{w}, \pi_{t}^{c}$ are import price, producer, and consumer inflation, respectively. Following McCarthy (2007), setting $\boldsymbol{B}$ to be equal to the Cholesky decomposition of $\boldsymbol{\Omega}, \boldsymbol{B} \boldsymbol{B}^{\prime}=\boldsymbol{\Omega}$ where $\boldsymbol{B}$ is lower triangular matrix, provides a simple integrated framework to track pass-through from exchange rate fluctuations to each stage of the distribution chain. Under this identification scheme the structural shocks $\boldsymbol{u}_{t}=\boldsymbol{B}^{-1} \boldsymbol{\varepsilon}_{t}$ are orthogonalized, namely, $\mathbb{E}\left(\boldsymbol{u}_{t} \boldsymbol{u}_{t}{ }^{\prime}\right)=\boldsymbol{I}_{n}$.

The relationship $\boldsymbol{\varepsilon}_{t}=\boldsymbol{B} \boldsymbol{u}_{t}$ (omitting the time subscripts to avoid clutter) implies the recursive structure

$$
\begin{aligned}
\varepsilon^{*} & =b_{11} u_{1}, \\
\varepsilon^{a} & =b_{21} u_{1}+b_{22} u_{2}+b_{23} u_{3}, \\
\varepsilon^{s} & =b_{31} u_{1}+b_{32} u_{2}+b_{33} u_{3}, \\
\varepsilon^{m} & =b_{41} u_{1}+b_{42} u_{2}+b_{43} u_{3}+b_{44} u_{4}, \\
\varepsilon^{w} & =b_{51} u_{1}+b_{52} u_{2}+b_{53} u_{3}+b_{54} u_{4}+b_{55} u_{5}, \\
\varepsilon^{c} & =b_{61} u_{1}+b_{62} u_{2}+b_{63} u_{3}+b_{64} u_{4}+b_{65} u_{5}+b_{66} u_{6},
\end{aligned}
$$


where the constraint $b_{23}=0$ must be imposed in order to achieve the identification of the structural shocks. The variable $u_{1}$ can be interpreted as a foreign supply shock and is identified solely from the dynamics of foreign inflation. On the other hand, demand shocks $\left(u_{2}\right)$ are identified from the dynamics of economic activity $\left(a_{t}\right)$ after taking into account the contemporaneous effect of the foreign shock. Similarly, exchange rate shocks $\left(u_{3}\right)$ are identified from the dynamics of exchange rate depreciation $\left(s_{t}\right)$ after controlling for the contemporaneous effects of the supply and demand shocks. Inflation innovations at each stage - import, producer, and consumer - are comprised of several components. The first three components are the effects of macroeconomic shocks $\left(u_{1}, u_{2}\right.$ and $\left.u_{3}\right)$. Next are the effects of shocks at the previous stages of the chain (for instance, $u_{4}$ and $u_{5}$ for $\varepsilon^{c}$ ) which can be thought of as changes in the pricing power and markups of firms at these stages. Finally, there is that stage's shock $\left(u_{6}\right)$.

Two points regarding the identification scheme are worth mentioning. Firstly, the recursive nature of $\boldsymbol{B}$, at least for the last three equations in (4), provides a straightforward model of pricing along a distribution. This allows import inflation shocks to affect domestic consumer inflation both directly and indirectly through their effects on producer inflation. Also, it prevents contemporaneous feedback: e.g., consumer inflation shocks affect inflation at the import and producer stages only through their effect on expected inflation in future periods.

Secondly, one issue that arises in using a Cholesky decomposition concerns the identification of aggregate demand and exchange rate shocks. Although the model assumes that economic activity is affected contemporaneously by foreign supply shocks and demand shocks, it truly may also be affected contemporaneously by exchange rate shocks. If so, $u_{2}$ and $u_{3}$ would be a combination of aggregate demand and exchange rate shocks. We perform robustness checks on this issue in section 3.3

\section{Estimation results}

This section presents the main results of the paper. A significant decrease in the pass-through estimates is documented, especially for producer and consumer prices. The shift is quick and coincides with the moment the Peruvian inflation reached international levels for the very first time in recent history. By then, the Peruvian economy had fulfilled all the conditions to adopt a fully-fledged inflation targeting regime. Thus, the Peruvian experience constitutes a neat example of the Taylor's hypothesis that a low inflation environment has been instrumental in the reduction of the exchange rate pass-through effect.

\subsection{The Peruvian disinflation and the inflation targeting regime}

In the early the 90s, the Central Reserve Bank of Peru (BCRP) embarked into a disinflation programme that brought inflation from hyperinflation (around 140 percent in 1991) down to single-digit levels (6.5 percent in 1997) and eventually to international levels (3.7 percent in 1999 and 2000). The process of disinflation was gradual as the BCRP slowly improved its credibility and built reputation as an inflation targeter. Aimed at reinforcing its ability to anchor inflation expectations, in 1994 the BCRP started announcing yearly target ranges.

Hence, after some years of decreasing inflation and inflation volatility, the Peruvian economy reached the conditions to consolidate price stability and to adopt a fully-fledge inflation targeting regime in 2002, when long-run targets were announced. This process was complemented with a definite change in the monetary policy operational target, from quantitative indicators such as the growth rate of money to short-run interbank interest rates. See Rossini and Vega (2008) for further details.

Figure 1 shows the evolution of inflation and the inflation forecasts made by economic agents from the private sector. It can clearly be seen that expectations have been anchored by the announced targets: inflation expectations have lied within the target range since the adoption of the inflation targeting regime. The inflation target has served as a benchmark for medium to long-run forecasting. This is true even in difficult years as from 2007 to 2009, when the economy was hit by large and persistent food price and oil shocks that deviated inflation from its target.

Given these dynamics, it can be concluded that the BCRP has managed to establish a credible regime of controlled inflation. The timing of events is crucial to understand the evolution of the institutional framework underlying the pass-through estimates below. 


\subsection{Benchmark results}

The appendix provides details on the data used and their sources. All variables enter the VAR as annualized percentage changes, except from economic activity that enters as a year-on-year change to control for seasonality. In the benchmark specification, foreign inflation $\pi_{t}^{*}$ is measured as the weighted average of the CPI inflations of the main Peruvian's trade partners, using trade weights; economic activity $a_{t}$ is calculated with a monthly gross domestic product (GDP) index; nominal depreciation $s_{t}$ is the variation of the nuevos soles (the Peruvian currency) per US dollar exchange rate; imports inflation in nuevos soles $\pi_{t}^{m}$ is the change of the wholesale price index of imported goods; producer inflation $\pi_{t}^{w}$ is the change of the wholesale price index of nationally produced goods; finally, $\pi_{t}^{c}$ is CPI inflation.

In order to study the evolution of the pass-through effect, the VAR model is estimated using rolling windows of fixed size, set to $w=72$, i.e. each sample contains 6 years on monthly data. The first window runs from January 1992 to January 1998. Then, we add one period of observation at a time and drop an initial period of observation such that the window size remains unchanged, and repeat this process until we reach the last rolling window sample that spans from April 2005 to April 2011. It can be argued that a sample of $w=72$ observations, though relatively small, is reasonable to estimate a VAR model with 6 variables, as long as it is parsimonious. For this reason, we perform an automatic specification search to determine the lag length of the VAR $m$ for each subsample. Given a window, we choose $m$ among specifications from $m=1$ to $m=6$ to minimise the Bayesian (Schwartz) information criterion (BIC), which is known to put more weight on relatively small models.

For concreteness, we focus our attention on pass-through estimates in the long-run $\psi_{\infty}$, with occasional references to the pass-through on impact $\psi_{0}$. Figure 2 shows the results, where the horizontal axis corresponds to the last observation in a window. To ease the visual inspection of the results, we have included a moving average of the long-run pass-through and of its $90 \%$ confidence interval. More precisely, the same moving average was applied to the time series of rolling estimates of $\psi_{\infty}$ and that of $\psi_{\infty} \pm 1.65 \times$ standard error $\left(\psi_{\infty}\right)$.

It can be seen from Figure 2(a) that the long-run pass-through effect has declined over the period of analysis in all stages of the distribution change. In particular, the pass-through effect to imports inflation reduces gradually from a point estimate of around 70 percent by the end of the 90 s to 10 percent one decade later. Nonetheless, what is remarkable is the sharp and quite significant decrease of both the impact and long-run pass-through in the second stage, related to producer prices: from about 70 percent to between 20 and 30 percent. The combination of these trends leads to a significant reduction in the pass-through to consumer prices, from 60 percent to roughly 10 percent by the end of our sample.

The conspicuous decrease in the pass-through to producer and consumer prices unveils a regime switch in the price setting behaviour of firms and retailers in the last stages of the distribution chain. Even though the Peruvian economy has experienced some productivity gains in its manufacturing sector, its cost composition and its dependence on imported inputs have barely changed. Even so, the pace of such changes are usually gradual and is unlikely to explain such a sudden decrease in the pass-through. Thus, the timing of the decrease favours an interpretation in the line of Taylor (2000). It is no coincidence that the shift occurs shortly before the adoption of the fully-fledged inflation targeting regime, in particular when inflation reached for the very first time a value below 5 percent (in 1999 inflation was 3.7 percent), and it stops exhibiting a decreasing trend to finally stabilise at international levels.

Figure 2(b) shows the dynamics of the pass-through effects during the operation of the inflation targeting scheme. Although some of the short-run increases and decreases in the estimates can be attributed to the evolution of the trade account or to the economy's degree of openness, their effects are dwarfed by the decline at the beginning of the 2000s. Besides, formal testing procedures cannot reject the hypothesis that at given two periods after the adoption of the inflation targeting scheme the estimates are statistically the same. Visually, in the vast majority of occasions, and in all distribution stages, the point estimates at time $t_{1}$ lie between the $90 \%$ confidence interval computed at time $t_{0}$, for $\left\{t_{0}, t_{1}\right\}>2002$. In other words, time-variation in the post inflation targeting sample may be attributed to sampling error rather than to a fundamental change in the parameters of the model. 


\subsection{Robustness checks}

In order to test the sensitivity of the results above, and especially to assess whether the documented decline in the pass-through is an artifact of the data or comes from an incorrect identification of shocks, we perform three sets of robustness checks.

The first aims to investigate whether estimates are sensitive to the definition of the variables used in the VAR:

(a) In the base model, foreign inflation $\pi_{t}^{*}$ is measured from a trade-weighted aggregate of Peru's trade partners CPI indices in US\$, which is the index used for official computations of the real effective exchange rate. Since $\pi_{t}^{*}$ is based on CPI data, it may not react strongly or timely enough to commodity price shocks that are likely to affect Peruvian inflation (such as food prices booms and busts), and that may be important to separate adequately the foreign from the exchange rate shocks. An alternative is to consider the imports price (also in US\$) used in the computations of the terms of trade, which features the foreign CPI inflation as a component and also includes commodity prices.

(b) Similarly, economic activity $a_{t}$ is measured by the growth rate of a GDP index in the base model, which includes certain components, such as exports, that are unlikely to affect local inflation. An alternative measure, presumably more related to domestic pressures on prices, is to use growth rate of a domestic demand index.

(c) The nominal exchange rate in the base model is bilateral: nuevos soles per US dollar. Even though the US is one of the most important trade and investment partner of Peru, there are others like the Eurozone or China with comparable trade and capital flows. This calls for viewing $s_{t}$ as the change of an effective exchange rate. Thus, we use the price in nuevos soles of a weighted average of a basket of foreign currencies, employed also for the official real effective exchange rate statistics. Consistently with this way of measuring the nominal exchange rate, in this exercise foreign inflation $\pi_{t}^{*}$ corresponds to a trade-weighted CPI index in units of the basket of foreign currencies.

(d) Another version of the model uses CPI "core" inflation instead of CPI inflation. The former is sensibly smoother and marks the trend of the latter, and it is well-known that such measures of underlying inflation are preferred for monetary policy analysis, and for assessments of medium-term inflation. Core inflation excludes some volatile items from the CPI basket. Most of these items are sensitive to world commodity prices, and their exclusion may change the pass-through profile through time.

The second set is related to the methods used to identify the exchange rate shock:

(e) It is well known that the recursive structure imposed by the Cholesky factorisation in a system like (4) is not invariant to the ordering of the variables in the VAR, so that different ordering may lead to different conclusions. Since this identification assumption is not testable, it is of interest to determine how the structural analysis based on the IRF is influenced by alternative causal orderings. It can be argued that the first and the last three equations in system (4) correspond to a conceptually correct ordering: whereas the first equation identifies a foreign shock exogenous to a small open economy, the last group of equations help identifying markup shocks hitting at different stages of the distribution chain. Since no such clear-cut justification is found for (4b) and (4c), it is natural to reverse the ordering of these equations as part of the sensitivity analysis. Thus, we arrive to a competing exactly identified structure by imposing the constraint $b_{32}=0$ in (4c) and by letting $b_{23} \neq 0$ in (4b).

(f) An alternative approach is to compute pass-through estimates based on the generalized impulse response functions (GIRFs) advanced in Pesaran and Shin (1998). Instead of controlling the impact of correlation among innovations (as it is usual in the structural VAR tradition), GIRFs follow the idea of a mean impulse response: when one variable is shocked, other variables also vary as implied by their historical patterns of correlations. The computations involved are as previously described with $\boldsymbol{\delta}$ redefined as $\boldsymbol{\delta} \propto \boldsymbol{\Omega} \boldsymbol{e}_{k}$, i.e. setting $\boldsymbol{B}=\boldsymbol{\Omega}$ in (3), an expression that comes after hitting the $k$-th innovation of the system and integrating out, 
under normality, the effects of remaining innovations. Unlike orthogonalized shocks, GIRFs are invariant to the ordering of the variables in the VAR.

Finally, the third set of robustness checks involves varying some of the parameters used in the rolling estimations:

(g) The size of the rolling samples in the previous section was set to $w=72$ observations, i.e. 6 years worth of monthly data. It can be argued that this is a relatively small sample size to estimate a VAR model, and that for this reason the BIC as the lag length criterion would tend to favour, more often than normal, specifications that are too parsimonious ( small $\mathrm{m}$ ). To confirm or deny this claim, and within the constraints imposed by data availability, we repeat the rolling estimations with $w=96$, i.e. 8 years of monthly data. The increase in the sample size may induce BIC to choose specifications with richer dynamics (larger $m$ ) that can affect the pass-through profiles in Figure 2

(h) Rolling windows estimates may be misleading since they would display time-variation even if the true underlying parameters are constant. This is due to the presence of a random walk emerging from the accumulation of $w$ sampling errors across windows. In the constant parameters case, finite sample biases remain of order $O_{p}(1 / w)$.

The time-varying nature of the pass-through estimates can be assessed alternatively using recursive estimations, which are more reliable in timing parameter shifts and in unveiling the nature of finite sample biases. For instance, in the constant parameters case, finite sample biases approach zero as the window size increases. Here, the first observation if fixed (at January 1993) and the VAR model is estimated repeatedly by adding one observation at each time. The results are pass-through estimates based on an increasing sample size, from $w \simeq 60$ to $w \simeq 220$.

Figure 3 shows the alternative estimations. Three exercises display the largest differences with respect to the benchmark results in Figure 2 a), and are thus worth commenting. The first one is panel (c), where the effective exchange rate is used in lieu of the biltateral. The pass-through to import prices is generally higher whereas the pass-through to producer and consumer inflation is slightly more volatile, a result that may follow from the fact that the effective exchange rate has been less volatile than the bilateral (see Figure 4). The second one corresponds to panel (d) where the decrease in the pass-through consumer inflation as measured by the CPI core inflation is slower. Nevertheless, it still transits from around 60 to 10 percent as in the base model. This result may be linked to the nature of CPI core inflation: it is roughly a trend of CPI inflation, thus more persistent but centered over long horizons about the same values as the CPI total inflation (see Figure 4). Finally, the recursive estimation of panel (h) does not exhibit the same dynamics of the pass-through estimates after the adoption of the inflation targeting regime. This confirms the conclusion that most of the pass-through dynamics are simply due to the accumulation of sampling errors, and not necessarily reflecting a true change in the underlying VAR parameters. However, the sharp decline of the pass-through to producer and consumer prices (both on impact and in the long-run) at the beginning of the 2000s is still prominent, and cannot be attributed to sampling variation.

All in all, the results are remarkably robust, and the main conclusions on the behaviour of the pass-through hold qualitatively, and almost quantitatively.

\section{Concluding remarks}

Conventional wisdom on the importance of the pass-through effect for policy design in open economies points out that a low pass-through grants the central bank degrees of freedom to conduct an independent monetary policy, and eases the implementation of an inflation targeting regime. In this sense, the estimations above for Peru close a virtuous circle: having reached the conditions to adopt an inflation targeting regime, has itself contributed significantly to the reduction of the pass-through.

The converse phenomenon is another important policy implication of our analysis. The observed reduction in the exchange rate pass-through should not be regarded as a permanent change. Should the inflation level and its 
persistence increase in the future, say as the result of large shocks to commodity prices, we would expect to see an increase in the pass-through that, in turn, could expedite inflationary pressures again.

Even though the results above are specific to the Peruvian case, they may share similarities with other emerging economies, just as their recent inflationary experiences do. If this is the case, the conclusion by Vega and Winkelried (2005) that the inflation targeting regime exerts positive outcomes when adopted by a developing country, could be complemented with a low pass-through effect amongst its benefits. We reckon that an interesting avenue for future research is to replicate the empirical analysis in this paper to other developing countries.

\section{A Data appendix}

We use monthly data from January 1992 to April 2011. All variables enter the model as annualised percentage changes, except for economic activity that is a year-on-year change.

Table 1 describes the data and Figure 4 plots them. For each variable in the VAR the first definition is used in the base model of section 3.2. whereas the others feature the robustness checks of section 3.3. Most of the series are available online at the BCRP's website (http://www.bcrp.gob.pe/statistics.html) and are regularly published in its Weekly Report (Nota Semanal). When applicable, the column "Source" in Table 1 shows the page number of the Weekly Report where each series can be found. The data on wholesale price indices used to measure importer and producer prices come from the National Statistical Office (INEI) and are also available online (http://iinei.inei.gob.pe/iinei/siemweb/publico).

Table 1. Data description

\begin{tabular}{clcc}
\hline Variable & \multicolumn{1}{c}{ Definition } & Source & Outliers \\
\hline \multirow{2}{*}{$\pi^{*}$} & Multilateral foreign price index in US\$ $(1994=100)$ & 45 & $2008.03,2008.10$ \\
& Terms of trade, imports price index $(1994=100)$ & 60 & 2004.01 \\
& Multilateral foreign price index (basket of currencies, $1994=100)$ & 45 & \\
\multirow{2}{*}{$a$} & GDP $(1994=100)$ & 63 & \\
& Domestic demand $(1994=100)$ & 63 & 2006.03 \\
\multirow{2}{*}{$s$} & Banking system nominal exchange rate S/. per US\$, ask & 40 & $1999.01,2007.10,2008.05$ \\
& Nominal exchange rate (S/. per basket) & 43 & $1999.02,2008.06$ \\
$\pi^{w}$ & Wholesale price index - imported products $(1994=100)$ & INEI & $2006.03,2008.02$ \\
$\pi^{m}$ & Wholesale price index - domestic products $(1994=100)$ & INEI & $2009.01,2009.02$ \\
\multirow{2}{*}{$\pi^{c}$} & Lima CPI (2009 = 100) & 50 & 2002.11 \\
& Lima core inflation $(2009=100)$ & 50 & $2006.02,2007.11,2011.03$ \\
\hline
\end{tabular}

At monthly frequency, the data are inevitably volatile. Certain unmodeled external events, such as the boom in commodity prices during 2007-2008 and the financial crises during 1998-1999 and 2008-2009, produced aberrant observations in our sample that can have profound effects on the VAR estimates. In order to control for these data irregularities, the reduced form VAR (1) is augmented as

$$
\boldsymbol{y}_{t}=\boldsymbol{\alpha}+\boldsymbol{A}(L) \boldsymbol{y}_{t-1}+\boldsymbol{\phi} D_{t}+\boldsymbol{\varepsilon}_{t},
$$

where $D_{t}$ denotes an impulse dummy variable that equals one in period $t$ if any of the variables in the VAR $\boldsymbol{y}_{t}$ exhibits an outlier in $t$. The outlier detection procedure is somehow standard. First, the residuals of a VAR using the whole sample and the BIC for the lag length selection are recorded. Then, outliers correspond to observations where a residual lies outside the band given by a 24-month moving average plus/mins 3 times the full-sample standard deviation. Table 1 shows the dates where an outlier is found in each series. 


\section{References}

Adolfson, M. (2007), "Incomplete exchange rate pass-through and simple monetary policy rules", Journal of International Money and Finance, 26(3), 468-494.

Campa, J. and L. Goldberg (2005), "Exchange rate pass-through into imports prices", Review of Economics and Statistics, 87(4), 679-690.

Carrera, C. and M. Binici (2006), "Exchange rate pass-through and monetary policy: Evidence from OECD countries", Central Reserve Bank of Peru, Working paper 2006-009.

Castillo, P., L. R. Maertens and G. Rodríguez (2011), "Does the exchange rate pass-thorugh into prices change when inflation targeting is adopted? The Peruvian case study between 1994-2007”, Pontificia Universidad Católica del Perú, Documento de trabajo 314.

Choudhri, E. U. and D. S. Hakura (2006), "Exchange rate pass-through to domestic prices: Does the inflationary environment matter?”, Journal of International Money and Finance, 25(4), 614-639.

Clark, T. E. (1999), "The responses of prices at different stages of production to monetary policy shocks", Review of Economics and Statistics, 81(3), 420-433.

Flamini, A. (2007), "Inflation targeting and exchange rate pass-through", Journal of International Money and Finance, 26(7), 1113-1150.

Goldberg, P. K. and M. M. Knetter (1997), “Goods prices and exchange rates: What have we learned?", Journal of Economic Literature, 35(3), 1243-1272.

Hendry, D. F. (2006), "Robustifying forecasts from equilibrium-correction systems", Journal of Econometrics, 135(1-2), 399-426.

Marazzi, M. and N. Sheets (2007), "Declining exchange rate pass-through to U.S. import prices: The potential role of global factors", Journal of International Money and Finance, 26(6), 924-947.

McCarthy, J. (2007), "Pass-through of exchange rates and import prices to domestic inflation in some industrialized economies", Eastern Economic Journal, 33(4), 511-537.

Mihaljek, D. and M. Klau (2008), "Exchange rate pass-through in emerging market economies: what has changed and why?", in Bank for International Settlements (ed.), Transmission mechanisms for monetary policy in emerging market economies, 35, 103-130, Bank for International Settlements.

Pesaran, H. M. and Y. Shin, "Generalized impulse response analysis in linear multivariate models", Economics Letters, 58(1), 17-29.

Rossini, R. and M. Vega (2008), "The monetary policy transmission mechanism under financial dollarisation: the case of Peru 1996 - 2006", in Bank for International Settlements (ed.), Transmission mechanisms for monetary policy in emerging market economies, 35, 395-412, Bank for International Settlements.

Takhtamanova, Y. F. (2010), "Understanding changes in exchange rate pass-through", Journal of Macroeconomics, 32(4), 1118-1130.

Taylor, J. B. (2000), "Low inflation, pass-through, and the pricing power of firms", European Economic Review, 44(7), 1389-1408.

Vega, M. and D. Winkelried (2005), "Inflation targeting and inflation behavior: A succesful story?", International Journal of Central Banking, 1(3), 153-175.

Winkelried, D. (2003), ¿Es asimétrico el pass-through en el Perú?: Un análisis agregado”, Central Reserve Bank of Peru, Revista Estudios Económicos, issue 10. 
Figure 1. Inflation, inflation expectations and inflation targets in Peru (1994 - 2010)

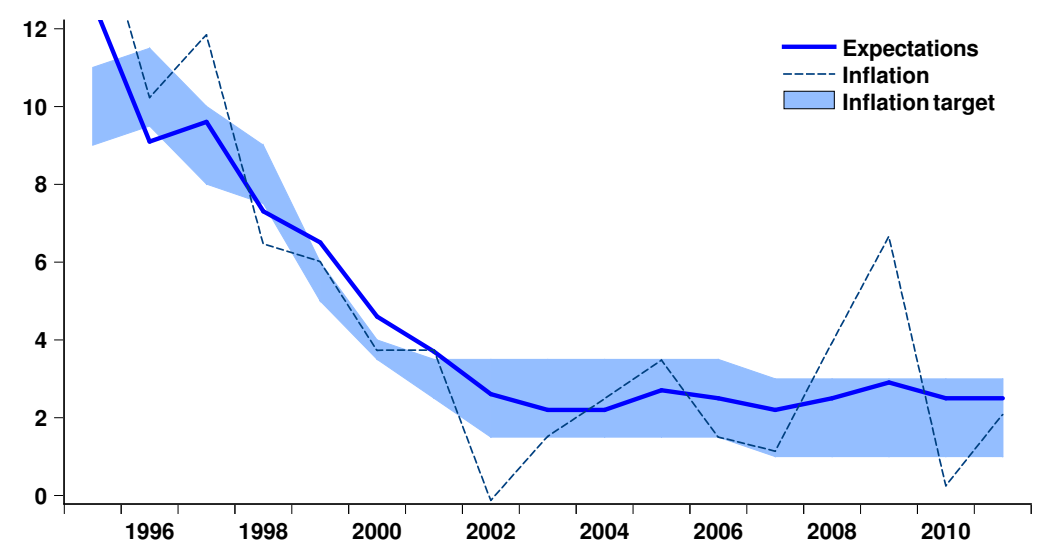

Notes: Data on inflation and the inflation target come from the Central Reserve Bank of Peru. Expectations are the two-year-ahead forecasts from the Latin American Consensus Forecast (as of the first issues in each year: February up to and including 2001, and January from 2002 onwards).

Figure 2. Rolling estimation results

(a) All the sample (1998 - 2001)
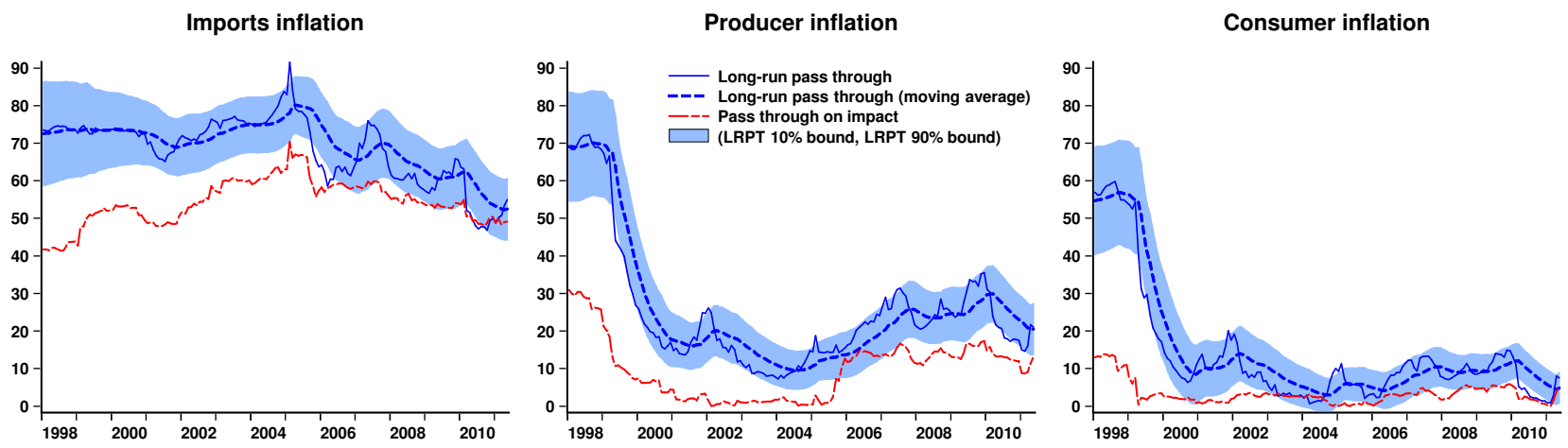

(b) After the adoption of an inflation targeting scheme in 2002
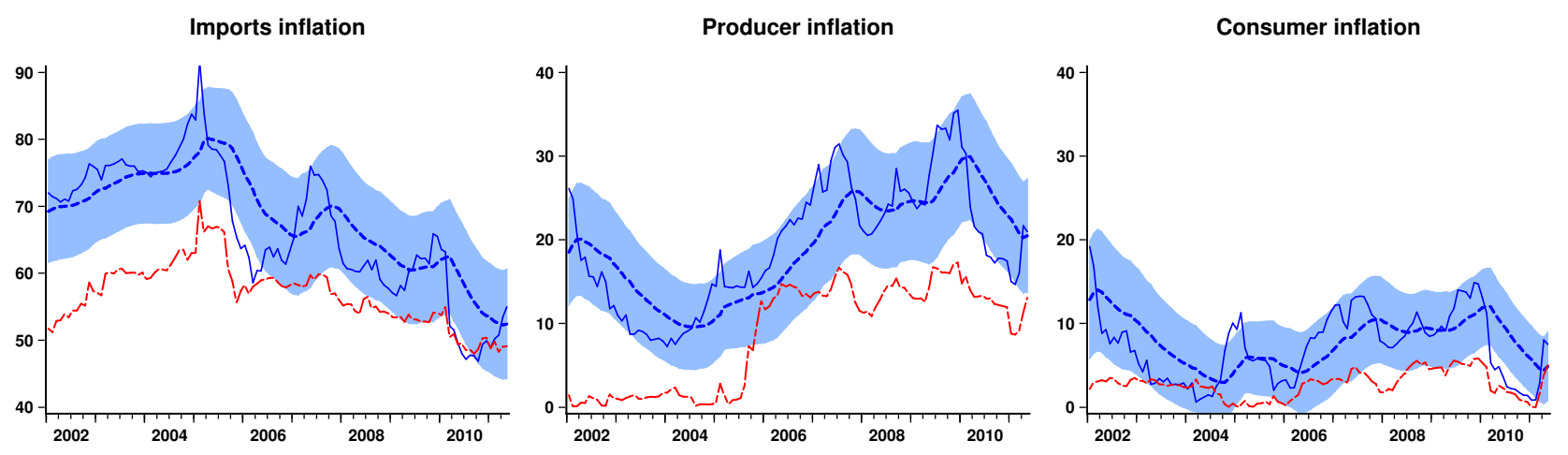
Figure 3. Robustness checks

(a) $\pi_{t}^{*}=$ Import prices inflation in US\$
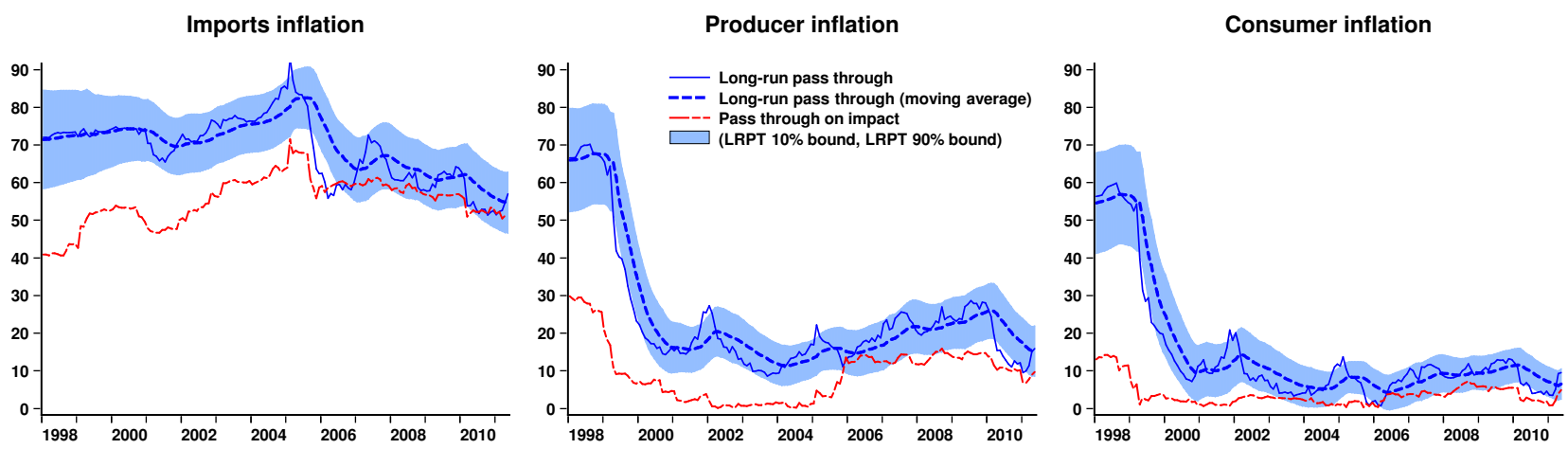

(b) $a_{t}=$ Domestic demand index growth
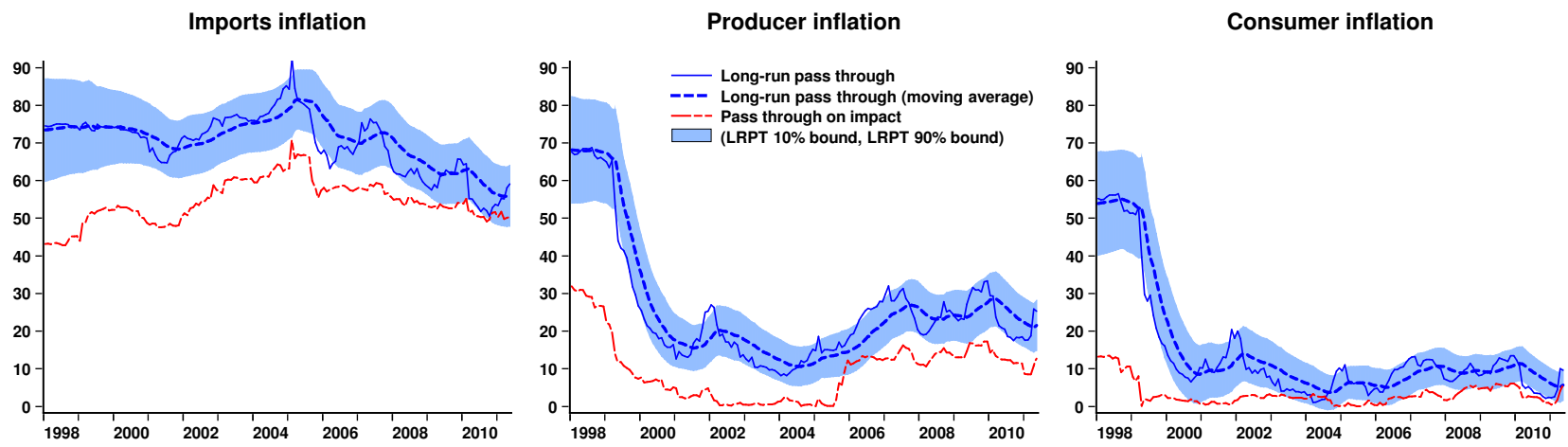

(c) $s_{t}=$ Nominal effective exchange rate depreciation, $\pi_{t}^{*}=$ foreign CPI inflation in terms of a basket of currencies

Imports inflation
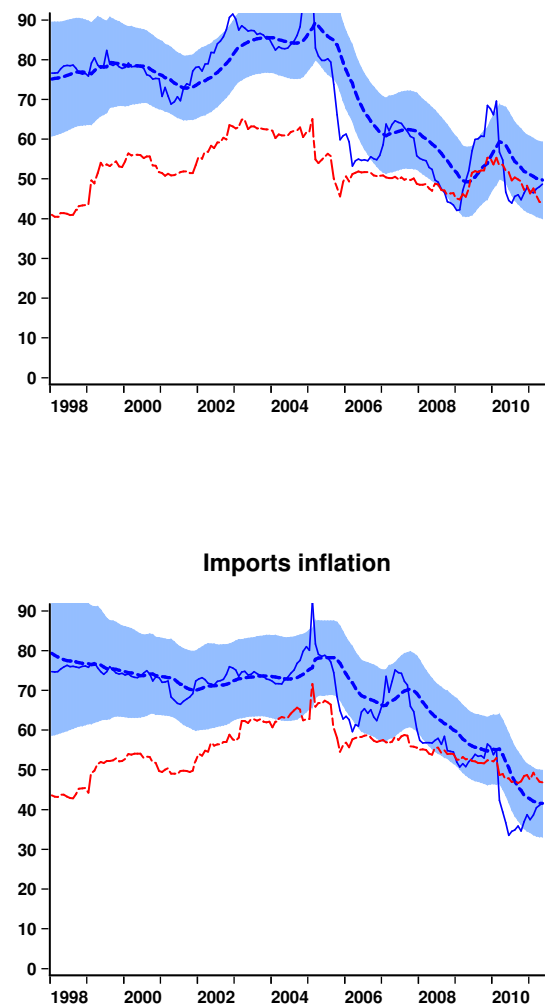

Producer inflation

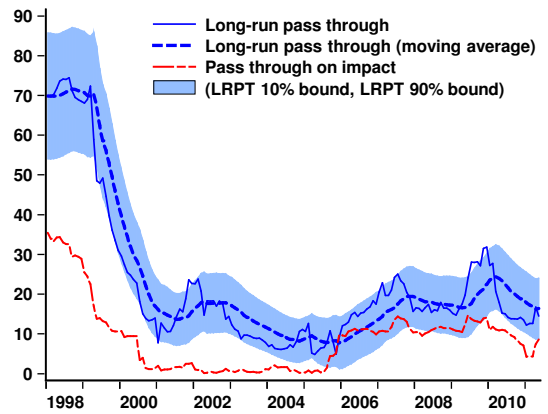

(d) $\pi_{t}^{c}=$ Core CPI inflation

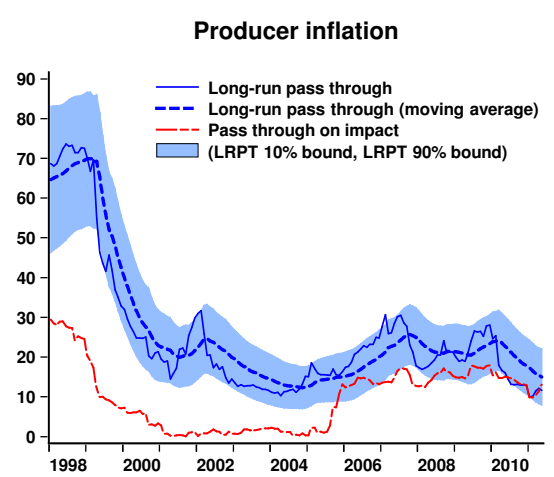

Consumer inflation

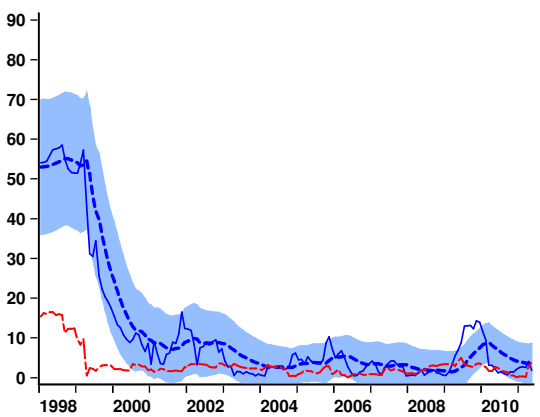

Consumer inflation

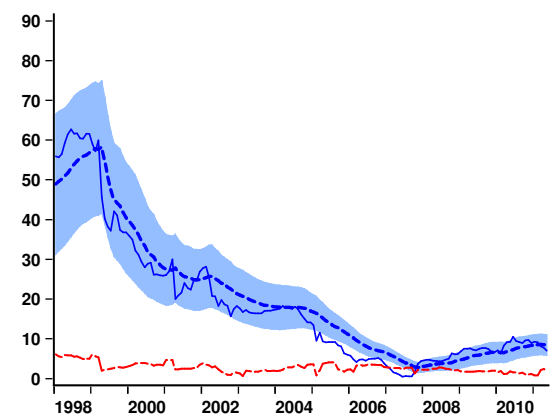


Figure 3 (continued). Robustness checks

(e) Alternative variable ordering

Imports inflation

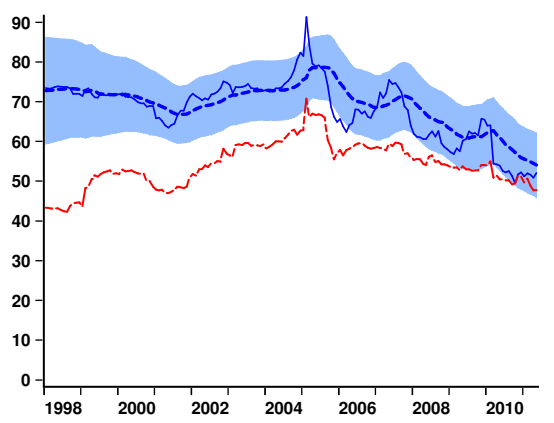

Producer inflation

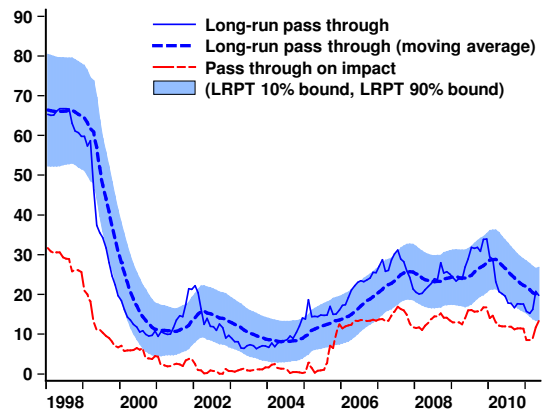

Consumer inflation

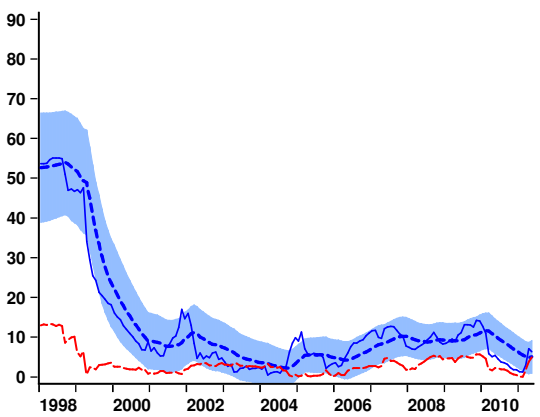

(f) Generalized impulse response functions

Imports inflation

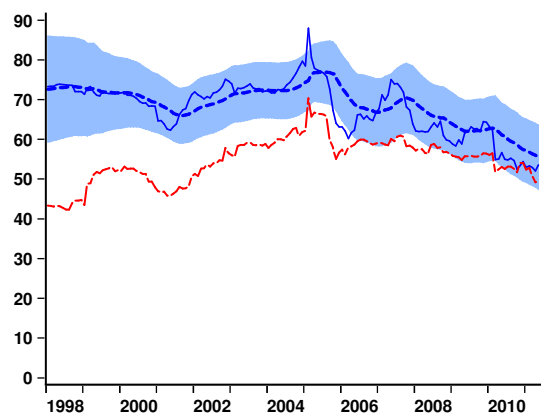

Producer inflation

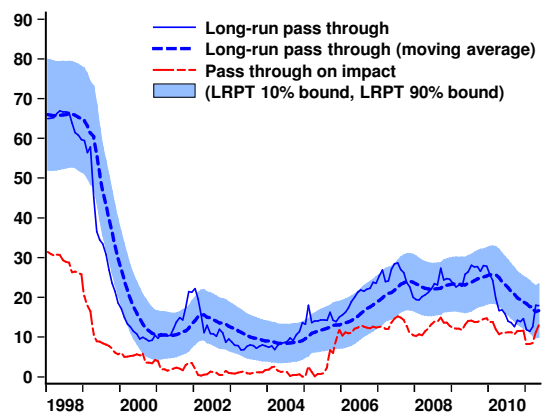

Consumer inflation

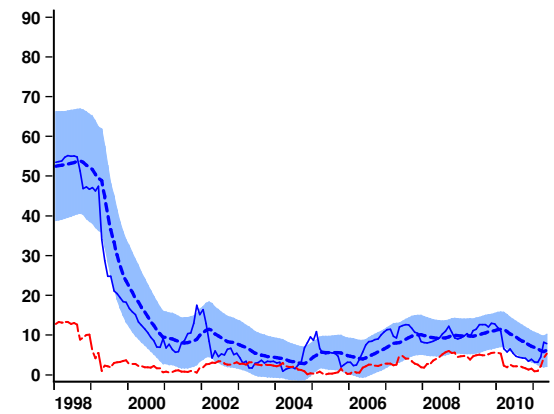

(g) Larger window size $(w=96)$

Imports inflation

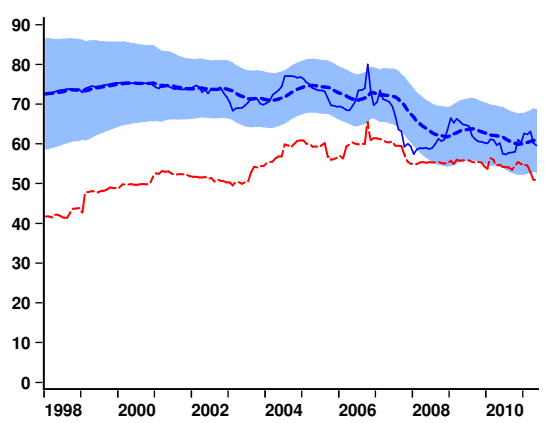

Producer inflation

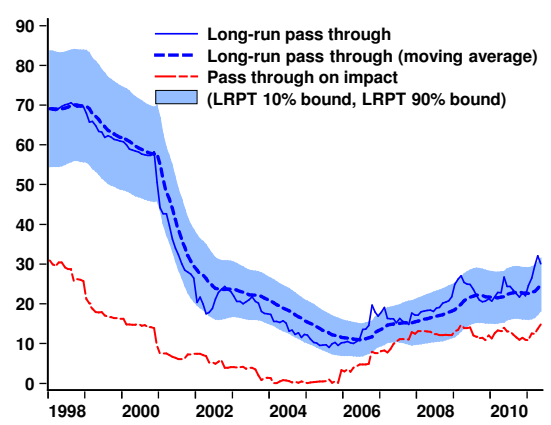

Consumer inflation

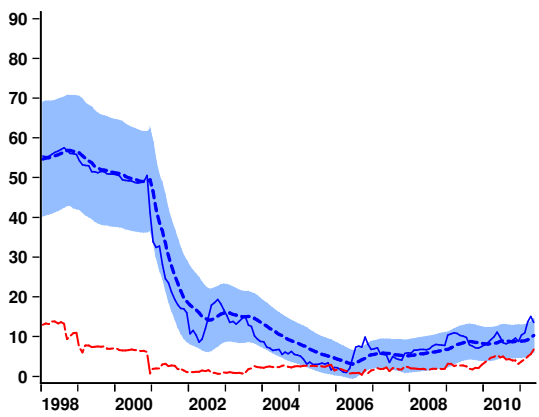

(h) Recursive estimation (increasing window size)

Imports inflation

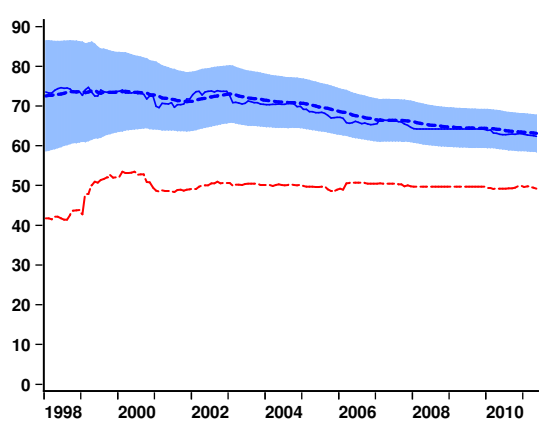

Producer inflation

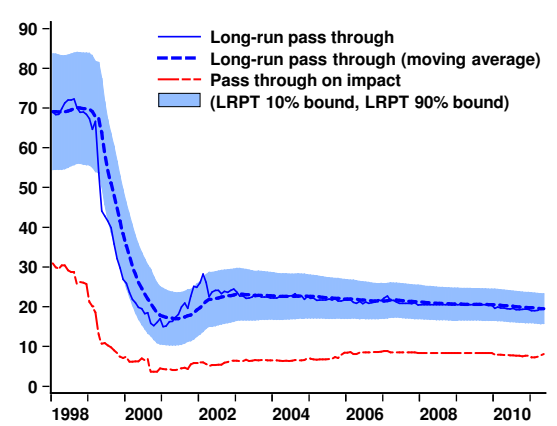

Consumer inflation

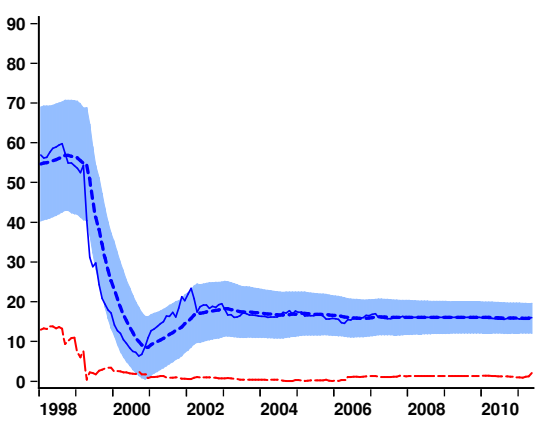


Figure 4. Data (year-on-year percentage changes)

Foreign inflation in US\$

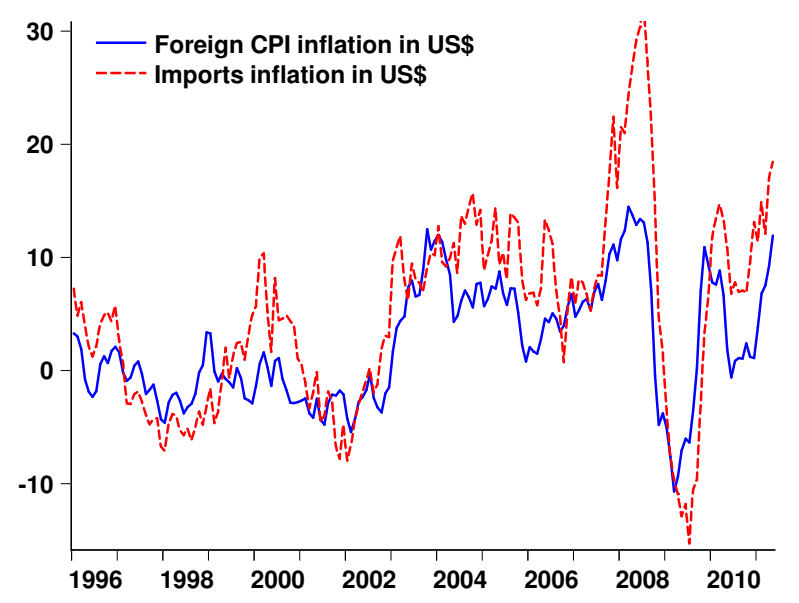

Nominal depreciation

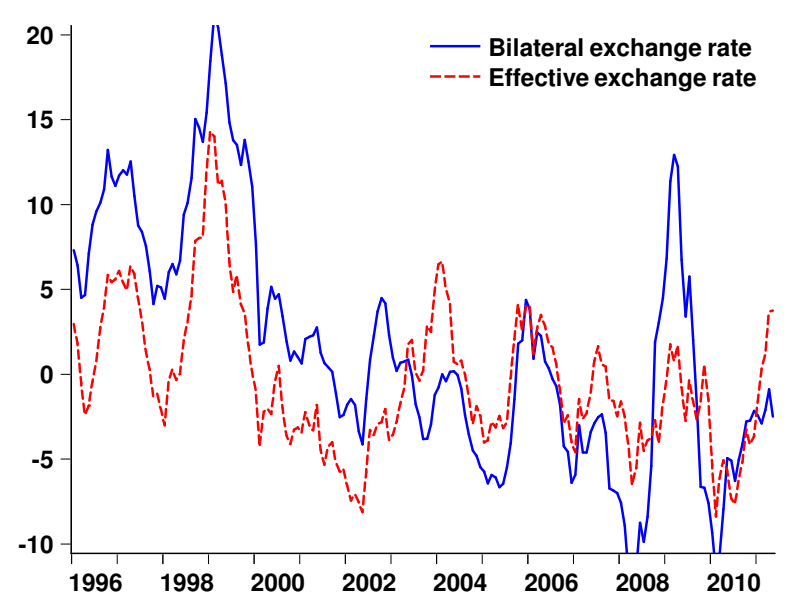

Domestic wholesale inflation

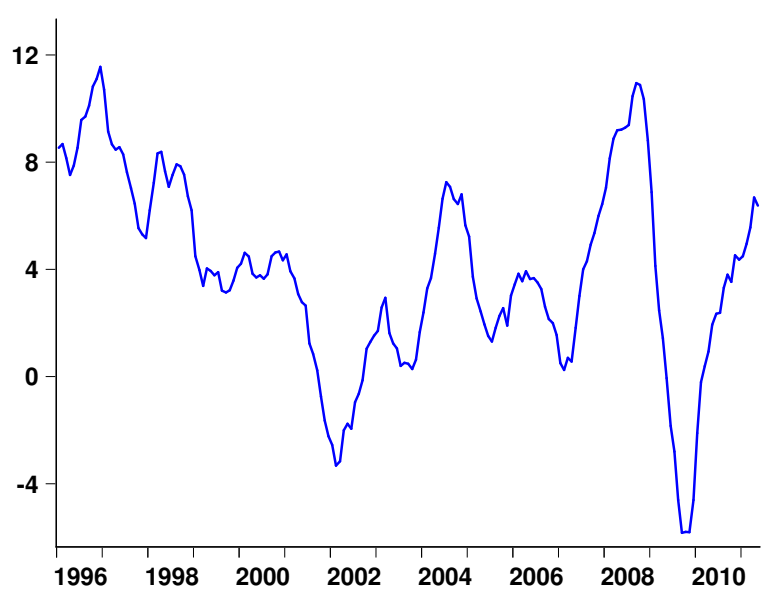

Economic activity
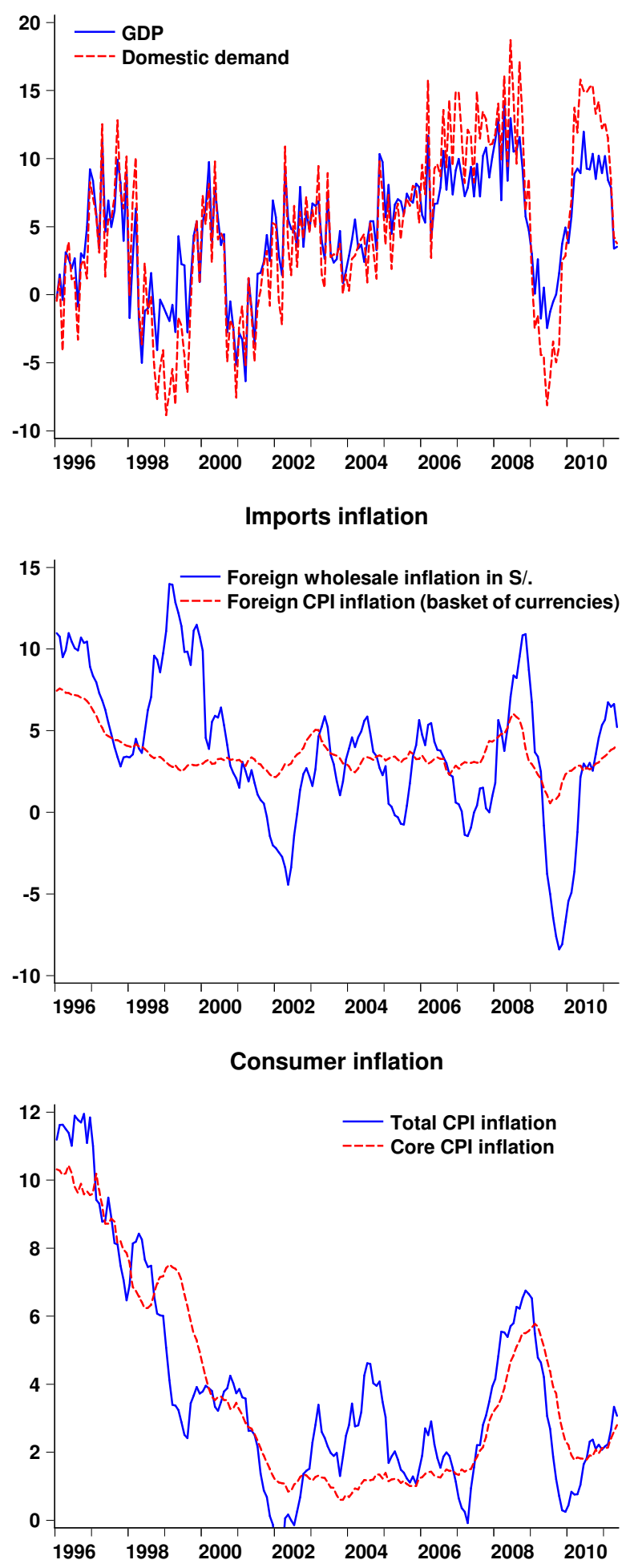